\title{
Editorial: Duckweed: Biological Chemistry and Applications
}

\author{
Marvin Edelman ${ }^{1 *}$, Klaus J. Appenroth ${ }^{2 *}$ and K. Sowjanya Sree ${ }^{3 *}$ \\ ${ }^{1}$ Department of Plant and Environmental Sciences, Weizmann Institute of Science, Rehovot, Israel, ${ }^{2}$ Matthias Schleiden \\ Institute - Plant Physiology, Friedrich Schiller University of Jena, Jena, Germany, ${ }^{3}$ Department of Environmental Science, \\ Central University of Kerala, Kasaragod, India
}

Keywords: Lemnaceae, molecular genetics, ecotoxicology, natural products, physiology

\section{Editorial on the Research Topic}

\section{Duckweed: Biological Chemistry and Applications}

The duckweeds (Lemnaceae) are a family of simple, higher plants at the far end of the monocotyledon subdivision. All of the 5 genera and the currently accepted 36 species (Bog et al., 2019, 2020) are aquatic, fresh water plants, mostly floaters or slightly submerged, and all have extremely reduced anatomies. The leaf-like frond of the largest (Spirodela polyrhiza, Giant Duckweed) is only $1-1.5 \mathrm{~cm}$ in size, while the smallest (Wolffia angusta), which also represents the smallest Angiosperm, measures less than $1 \mathrm{~mm}$. Duckweeds can flower, but normally propagate vegetatively, both in nature and in the laboratory, by budding from one or two meristematic zones within pockets in the frond. Species of the genera Spirodela, Landoltia, and Lemna have different numbers of adventitious roots with root caps, which may be more for stability in the water than nutrient uptake; the latter task is managed by the entire underside of the frond (Cedergreen and Madsen, 2002). Species of the genera Wolffiella and Wolffia are devoid of roots altogether.

As its name implies, duckweeds are a favorite food source for fowl, several fish and other animals as well (Appenroth et al., 2015). Under optimal conditions in nature or in the laboratory, several duckweed species can double their biomass almost daily representing the fastest growing Angiosperms (Sree et al., 2015). Depending on the cultivation conditions, the protein content of the biomass may reach up to $40 \%$ or more of the dry weight or the biomass may accumulate starch up to $50 \%$ of the dry weight. In controlled conditions, they can be grown axenically, either autotrophically, mixotrophically, or even heterotrophically (Landolt and Kandeler, 1987). In addition, the genomes of some duckweeds (e.g., S. polyrhiza; genome size, $160 \pm 3 \mathrm{Mbp} / 1 \mathrm{C}$ ) are among the smallest for a higher plant (Wang et al., 2011; Bog et al., 2015). Presently, the genome sequence of S. polyrhiza clone 9509 represents the "gold standard" for duckweed genomes (Hoang et al., 2018). Coupled with the increasing abilities of several groups to genetically transform (Vunsh et al., 2007) various species of this aquatic family (recently, by CRISPR-Cas, Liu et al., 2019), one can think of "upcoming model system" or "biotech applications."

The present Research Topic demonstrates that research and practical application of duckweeds is flourishing, drawing the attention of researchers as well as application specialists from across the globe. This Research Topic contains a review article about genomes and transcriptomes of duckweeds by An et al. and 12 original research articles organized into separate sections devoted to "Ecology and Biomonitoring," "Biochemistry and Physiology," and "Biotechnology."

In the section "Ecology and Biomonitoring," Paolacci et al. report about competition between two duckweed species, Lemna minuta and L. minor in Ireland. Yang et al. test the effect of heavy metal $\mathrm{Hg}^{2+}$ on three species, L. minor, L. gibba, and S. polyrhiza and investigate the criteria to use duckweed species either for biomonitoring or phytoremediation. Gilbert et al. show that the association between bacterial endophytes and duckweeds belonging to a particular genus correlates with the indole related compounds produced by those endophytes. 
In the following section "Biochemistry and Physiology," Appenroth et al. analyse both qualitatively and quantitatively the protein, fat, minerals, vitamins, and phytosterols, required for human nutrition, from all 11 species of Wolffia. Chakrabarti et al. report the profiles of amino- and fatty- acids in L. minor under non-sterile, mass production conditions, although the fertilizers used exclude use of the biomass for human nutrition. Utami et al. examine the effect of eight organic compounds including common phytohormones on L. minor and show that only ascorbic acid significantly stimulates biomass production. The cuticle on the abaxial and adaxial sides of duckweed is investigated by Borisjuk et al. who describe cuticle structure in relation to its function in interacting with different environments, like sunlight/air and nutrients/water. Evans et al. exploit the fact that duckweed can be cultivated under autotrophic, heterotrophic and mixotrophic conditions to apply $\mathrm{N}^{15}$-labeled nitrate and ammonium under these conditions and investigate the size and dynamics of amino acid pools. Pagliuso et al. investigate all five duckweed genera concerning relative growth rates and content of soluble and cell wall carbohydrates suggesting apiose level as a biomarker for growth capacity of duckweeds.

In the final section, "Biotechnology," Heenatigala et al. outline stable transformation of Wolffia globosa for the first time using

\section{REFERENCES}

Appenroth, K. J., Sree, K. S., Fakhoorian, T., and Lam, E. (2015). Resurgence of duckweed research and applications: report from the 3rd International Duckweed Conference. Plant Mol. Biol. 89, 647-654. doi: 10.1007/s11103-015-0396-9

Bog, M., Appenroth, K. J., and Sree, K. S. (2019) Duckweed (Lemnaceae): Its molecular taxonomy. Front. Sustain. Food Syst. 3, 117. doi: 10.3389/fsufs.2019.00117

Bog, M., Appenroth, K-J., and Sree, K. S. (2020). Key to the determination of taxa of Lemnaceae: an update. Nordic J. Bot. 38, 1-12. doi: 10.1111/njb.02658

Bog, M., Lautenschlager, U., Landrock, M. F., Landolt, E., Fuchs, J., Sree, K. S., et al. (2015). Genetic characterization and barcoding of taxa in the genera Landoltia and Spirodela (Lemnaceae) by three plastidic markers and amplified fragment length polymorphism (AFLP). Hydrobiologia 749, 169-182. doi: 10.1007/s10750-014-2163-3

Cedergreen, N., and Madsen, T. V. (2002). Nitrogen uptake by the floating macrophyte Lemna minor. New Phytol. 155, 285-292. doi: 10.1046/j.1469-8137.2002.00463.x

Hoang, P. N. T., Michael, T. P., Gilbert, S., Chu, P., Motley, S. T., Appenroth, K. J., et al. (2018). Generating a high-confidence reference genome map of the greater duckweed by integration of cytogenomic, optical mapping, and Oxford Nanopore technologies. Plant J. 96, 670-684. doi: 10.1111/tpj.14049

Landolt, E., and Kandeler, R. (1987). The Family of Lemnaceae - A Monographic Study. Vol. 2. Biosystematic Investigations in the Family of Duckweeds an Agrobacterium tumefaciens system, while Khvatkov et al. demonstrate stable transformation of Wolffia arrhiza to produce human granulocyte colony-stimulating factor (hG-CSF). Firsov et al. close the section with the expression of M2e from avian influenza virus $\mathrm{H} 5 \mathrm{~N} 1$ in transformed $L$. minor plants as a step in the development of broad-range oral vaccine against avian influenza.

\section{AUTHOR CONTRIBUTIONS}

All authors listed have drafted and revised the manuscript, and have made a substantial, direct and intellectual contribution to the work. Further, all the authors have approved it for publication.

\section{ACKNOWLEDGMENTS}

We thank Frontiers in Chemistry for their excellent support for this Research Topic. It is our great pleasure to also thank the Specialty Chief Editor of the section Agricultural Biological Chemistry, Dr. Autar Mattoo, USDA, USA for his constant support and encouragement in realizing our goal to generate the e-book on this Research Topic.
(Lemnaceae). Zurich: Veröffentlichungen des Geobotanischen Institutes der ETH, Stiftung Ruebel.

Liu, Y., Wang, Y., Xu, S., Tang, X., Zhao, J., Yu, C., et al. (2019). Efficient genetic transformation and RISPR/Cas9-mediated genome editing in Lemna aequinoctialis. Plant Biotechnol. J. 17, 2143-2152. doi: 10.1111/pbi.13128

Sree, K. S., Sudakaran, S., and Appenroth K. J. (2015). How fast can angiosperm grow? Species and clonal diversity of growth rates in the genus Wolffia (Lemnaceae). Acta Physiol. Plant. 37, 204. doi: 10.1007/s11738-015-1951-3

Vunsh, R., Li, J., Hanania, U., Edelman, M., Flaishman, M., Perl, A., et al. (2007). High expression of transgene protein in Spirodela. Plant Cell Rep. 26, 1511-1519. doi: 10.1007/s00299-007-0361-4

Wang, W., Kerstetter, R. A., and Michael, T.P. (2011). Evolution of genome size in duckweeds (Lemnaceae). J. Bot. 2011:570319. doi: 10.1155/2011/570319

Conflict of Interest: The authors declare that the research was conducted in the absence of any commercial or financial relationships that could be construed as a potential conflict of interest.

Copyright (c) 2020 Edelman, Appenroth and Sree. This is an open-access article distributed under the terms of the Creative Commons Attribution License (CC BY). The use, distribution or reproduction in other forums is permitted, provided the original author(s) and the copyright owner(s) are credited and that the original publication in this journal is cited, in accordance with accepted academic practice. No use, distribution or reproduction is permitted which does not comply with these terms. 